\title{
Review Article \\ Structural Health Monitoring Using High-Frequency Electromechanical Impedance Signatures
}

\author{
Wei $\operatorname{Yan}^{1}$ and W. Q. Chen ${ }^{2}$ \\ ${ }^{1}$ Faculty of Architectural, Civil Engineering and Environment, Ningbo University, Ningbo 315211, China \\ ${ }^{2}$ Department of Engineering Mechanics, Zhejiang University, Yuquan Campus, Hangzhou 310027, China
}

Correspondence should be addressed to W. Q. Chen, cwqcmx@yahoo.com.cn

Received 21 August 2009; Accepted 7 December 2009

Academic Editor: Piervincenzo Rizzo

Copyright (C) 2010 W. Yan and W. Q. Chen. This is an open access article distributed under the Creative Commons Attribution License, which permits unrestricted use, distribution, and reproduction in any medium, provided the original work is properly cited.

\begin{abstract}
An overview of recent advances in electromechanical impedance- (EMI-) based structural health monitoring is presented in this paper. The basic principle of the EMI method is to use high-frequency excitation to sense the local area of a structure. Changes in impedance indicate changes in the structure, which in turn indicate that damages appear. An accurate EMI model based on the method of reverberation-ray matrix is introduced to correlate changes in the signatures to physical parameters of structures for damage detection. Comparison with other numerical results and experimental data validates the present model. A brief remark of the feasibility of implementing the EMI method is considered and the effects of some physical parameters on EMI technique are also discussed.
\end{abstract}

\section{Introduction}

Over the last decades, structural health monitoring (SHM) has been recognized as a useful tool for improving the safety and reliability of structures and to thereby reduce their operational cost [1]. Many SHM techniques thus have been developed in the literature [2-4] to quantify and locate the damages in the structures, based on either the global or the local interrogation of the structures [5]. Although these SHM methods have their specific advantages for detecting damages in the structures, the existent drawbacks may limit their applications on some aspects. For example, in global dynamic techniques, it is well known that the structure is subjected to low-frequency excitations and only the first few mode shapes and their corresponding natural frequencies can be accurately extracted. Because localized damages find it hard to alter global parameters such as natural frequency, curvature mode shape, and mode shape data, only large damages can be detected. Meanwhile, signals obtained using these methods are more prone to contamination by ambient vibration noise at low frequencies less than $100 \mathrm{~Hz}$ particularly [5]. Other typical local techniques, such as ultrasonic techniques, acoustic emission, and impact echo testing, require expensive and sophisticated hardware as well as well-trained professional operators [6].

On the other hand, electromechanical impedance (EMI) based structural health monitoring has shown promising successes in monitoring and finding minor changes in structural integrity [5-9]. A key aspect of EMI method is the use of PZT patches as collocated sensors and actuators. To apply PZT as an actuator-sensor simultaneously, a PZT patch bonded to a structure is driven by a fixed alternating electric field. A surface charge is generated in response to an applied mechanical stress (direct effect), and conversely, a mechanical strain is produced in response to an applied electric field (converse effect). The electromechanical impedance defined as the ratio of the applied voltage and the resulting current can then be measured by a commercially available impedance analyzer. Although structural mechanical impedance related to structural properties such as stiffness and damping is difficult to obtain at first hand, the measured electrical impedance is directly related to mechanical impedance of the monitored structure and is also affected by the presence of structural damages. Thus, by observation of the electromechanical impedance of the PZT patch, one can obtain the information about the damage of the monitored structure [10]. 


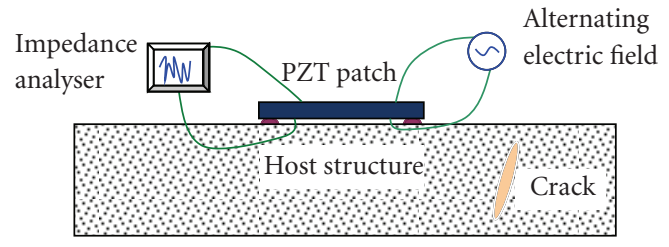

FIGURE 1: The sketch of a PZT patch bonded onto a damaged structure.

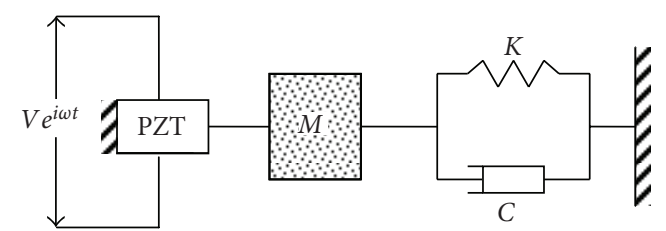

Figure 2: 1D model used to represent a PZT-driven dynamic structural system.

In general, the EMI signature is extracted at high frequencies (typically $10-500 \mathrm{kHz}$ ) [11]. At such frequencies, the wavelength of the excitation is very small and is therefore sensitive enough to detect minor changes in structural integrity. Many experimental investigations $[5,12-19]$ have shown the specific advantages of EMI technique over the conventional nondestructive evaluation methods. Sun et al. [12] first used EMI technique to examine a lab-sized truss structure. Ayres et al. [13] presented this qualitative impedance-based health monitoring method in real-time damage evaluation of civil infrastructures such as bridge joints. Soh et al. [14] studied the performance of smart piezoceramic patches in health monitoring of a reinforced concrete bridge at various stages during the loading process. Park et al. [15-17] demonstrated the capability and the effectiveness of this technology to detect damages of compositereinforced concrete walls, a 1/4-scale bridge element, and a pipe joint, respectively. Bhalla and Soh [5] discussed the feasibility of employing impedance signatures in monitoring the conditions of RC structures subjected to base vibration. Bois et al. $[18,19]$ detect a single delamination in a laminated composite plate via the EMI signatures of a piezoelectric transducer cemented onto the structure. These experimental researches indicate that the collection and processing of electromechanical impedance signatures are very easy to implement via an Agilent 4294A impedance analyzer and the EMI technique is highly sensitive to detect minor changes in structural integrity using measured data. However, an ideal robust damage detection scheme cannot only identify damages at a very early stage but also provide some estimate of the extent or severity of the damage and even locate the damage within the sensor resolution being used [20]. Thus, appropriate tools of simulation are necessary for monitoring system adapted to monitored structures.

The overview of the impedance method up to 2003 was previously summarized in [21]. The paper aims to give an updated overview of the recent advances in the EMI-based structural health monitoring. The basic principle of the EMI technique is first reviewed in Section 2. The recent developed approach, which integrates an accurate EMI model, in which both inertia effect of the PZT patch and the bonding property of adhesive are taken into consideration, with a stable high-frequency structural dynamics analysis method, the method of reverberation-ray matrix, is described in Section 3. Based on various sources in literature, Section 4 presents a discussion on the proper selection of parameters associated with the EMI-technique. Some recent applications of the EMI-based SHM method to complex configurations are noticed in Section 5. The paper ends with a brief summary.

\section{Conventional EMI Models}

Liang et al. [22] addressed that both approaches including a static approach and a dynamic finite element approach have some drawbacks in analyzing the dynamic response of active material systems and the impedance modeling technique is more suitable to reflect the physical essence of an active system. A simple 1-D model is then constructed to describe the interaction between a PZT patch and its host structure as shown in Figure 1. The PZT patch is bonded perfectly to the surface of the structure using a high-strength adhesive to ensure a better mechanical interaction and is assumed as a thin bar undergoing axial vibration in response to applied alternating voltage. A single-degree-of-freedom system is then considered as shown in Figure 2, in which one end of the PZT bar is fixed and the other end is connected to the host structure. According to this model, the constitutive relation of the PZT patch may be expressed as follows [22]:

$$
S_{1}=\bar{s}_{11}^{E} T_{1}+d_{31} E, D_{3}=\bar{\varepsilon}_{33}^{T} E+d_{31} T_{1},
$$

where $S_{1}$ is strain, $T_{1}$ the stress, $\bar{s}_{11}^{E}$ the complex compliance at zero electric field, $d_{31}$ the piezoelectric constant, and $D_{3}$ the electric displacement; $\bar{\varepsilon}_{33}^{T}=\varepsilon_{33}^{T}(1-\delta \mathrm{i})$ is the complex dielectric constant and $\delta$ is the dielectric loss factor. By solving the equation for the PZT bar connected to the external mechanical point impedance of the structure, the following expression of electrical admittance (inverse of impedance) in frequency domain can be obtained [23]:

$$
Y=i \omega a\left[\varepsilon_{33}^{T}(1-i \delta)-\frac{Z_{s}}{Z_{s}+Z_{p}} d_{31}^{2} \bar{E}_{p}\right],
$$

where $Y$ is the electrical admittance, $Z_{p}$ and $Z_{s}$ are the mechanical impedances of the PZT and the structure, respectively, $\bar{E}_{p}$ and $a$ are the complex Young's modulus and the geometric constant of the PZT patch, respectively, and $\omega$ is the circular frequency. It should be noted that although (2) is derived from a single-degree-of-freedom system, it is still applicable for 2D or very complex structures [16].

Although a good match between the predicted solutions by $1-\mathrm{D}$ impedance model $[22,23]$ and the experimental results was achieved, Zhou et al. [24] pointed out that the mechanical impedance coupling in different coordinate directions should be considered for two-dimensional structures and the cross impedance of the host structure has an 
impact on the transducer dynamics. With due derivation, the analytical expression of electrical admittance was then obtained based on two-dimensional impedance model [25]:

$$
\begin{aligned}
Y=\mathrm{i} \omega \frac{w_{p} l_{p}}{h_{p}}[ & \bar{\varepsilon}_{33}^{T}-\frac{2 d_{31}^{2} E_{p}}{(1-\nu)} \\
& \left.+\frac{d_{31}^{2} E_{p}}{(1-v)}\left\{\frac{\sin \kappa l_{p}}{l_{p}} \frac{\sin \kappa w_{p}}{w_{p}}\right\} \mathbf{N}^{-1}\left\{\begin{array}{l}
1 \\
1
\end{array}\right\}\right],
\end{aligned}
$$

where $\kappa=\omega \sqrt{\rho\left(1-v^{2}\right) / E_{p}}, v$ is Poisson's ratio; $h_{p}, w_{p}$ and $l_{p}$ are height, width, and length of the PZT wafer, respectively, and

$$
\mathbf{N}=\left[\begin{array}{cc}
\mathfrak{A}\left\{1-v \frac{w_{p}}{l_{p}} \frac{Z_{x y}}{Z_{a x x}}+\frac{Z_{x y}}{Z_{a x x}}\right\} & \mathfrak{B}\left\{\frac{l_{p}}{w_{p}} \frac{Z_{y x}}{Z_{a y y}}-v \frac{Z_{y y}}{Z_{a y y}}\right\} \\
\mathfrak{A}\left\{\frac{w_{p}}{l_{p}} \frac{Z_{x y}}{Z_{a x x}}-v \frac{Z_{x x}}{Z_{a x x}}\right\} & \mathfrak{B}\left\{1-v \frac{l_{p}}{w_{p}} \frac{Z_{y x}}{Z_{a y y}}+\frac{Z_{y y}}{Z_{a y y}}\right\}
\end{array}\right],
$$

where $\mathfrak{A}$ denotes $\kappa \cos \left(\kappa l_{p}\right), \mathfrak{B}$ denotes $\kappa \cos \left(\kappa w_{p}\right), Z_{x x}$ and $Z_{y y}$ are direct impedance, $Z_{x y}$ and $Z_{y x}$ are cross impedance of the host structure, respectively, and $Z_{a x x}$ and $Z_{a y y}$ are mechanical impedance of PZT patch in $x$ and $y$ directions, respectively.

Although the analytical derivations of above equations based on 2-D model are accurate themselves, the experimental difficulties limit their direct application for extraction of the host structure's mechanical impedance [26]. Thus, an effective mechanical impedance model $[26,27]$ was developed for improving the existing models, in which the mechanical interaction between the PZT patch and the host structure is not restricted at the PZT end points and it extends all over the finite sized PZT patch [26]. The finally obtained expression of electrical impedance is similar to that based on the classical one-dimensional model.

In the classical impedance model, a key problem is to obtain the analytical expression of the mechanical impedance $Z_{s}$, which is defined as $Z_{s}=F / \dot{x}$. (The impedance is determined by calculating the structural dynamic response, $\dot{x}$, corresponding to an arbitrary force $F$ at the driven point of the transducer [22].) For some simple structures, such as axial rods [28-30], beams [29-31], circular rings $[32,33]$, thin plates $[24,34,35]$, and shells [36], the analytical expression of the electromechanical impedance can be obtained readily based on the impedance modeling approach. However, when damages are induced in structures resulting in possibly inhomogeneity of material properties, analytical formulation is very difficult to be derived. For example, although Zagrai and Giurgiutiu [34] formulated analytical solutions based on EMI spectrum and mechanical response of a circular plate, when a damage is induced into the plate, the assumption for axis-symmetric axial and flexural vibration of circular plates is untenable and the analytical solutions does not hold for damage detection in the plates.

In order to obtain damage information by using changes in electromechanical impedance signature, it is necessary to establish improved correlation between EMI signature and changes in structural integrity. The finite element method (FEM) seems to be an alternative for the purpose $[6,11,30,37-40]$. However, FEM is usually subjected to an inherent disadvantage that a large number of finite elements and hence a large number of nodes should be involved for accurately predicting high-frequency response of a structure. As the finite element model becomes finer, the associated mass and stiffness matrices will increase in size and thus requirements on storage and computing time become critical. Other methods such as spectral element method [10] and Ritz method [35] have been applied to quantitatively identify structural damages. But, there are still certain difficulties associated with high-frequency analysis that limit their applications in quantitative analysis of impedance-based health monitoring. The transfer matrix method (TMM) is very powerful to analyze a structure consisting of many members (including damaged members) because the number of resultant simultaneous equations can be greatly reduced. However, significant numerical difficulty at high-frequency limits its application if computation is completely executed on a computer [41].

Moreover, it was assumed in the classical impedance model that the force transmission is just at two ends of PZT patch while the intermediate bonding layer was completely ignored based on pin force model. However, in the experiment of Soh et al. [14] and Giurgiutiu and Zagrai [29], it was found that the bonding between patch and host structure may be damaged. When disbonding occurs, the signature obtained from patch was distorted. Actually, it has been recognized by many researchers [40, 42-45] that the imperfect bonding of PZT patch influences the output EMI signatures significantly and should be investigated carefully.

Due to the complexity of PZT patch-adhesive-host structure coupled structural system and the difficulty of dynamic analysis in the high-frequency range as mentioned above, most existent analytical models of EMI technique fail to correlate changes in the signatures to physical parameters of structures and could not provide further information about the nature of damage. In order to develop a more accurate model to improve sensitivity of impedance signature to damages in structures, two key issues should be dealt with, one is to seek for an appropriate modeling to simulate the behavior of the PZT patch-adhesive-host structure coupled structural system, and the other is to find a powerful highfrequency dynamic analysis technique.

\section{Accurate EMI Models Based on MRRM}

In some existent EMI model [26, 27, 42], the inertial term of PZT patch was neglected and the mechanical impedance of host structure was assumed to be a constant at all points of the patch attachment. However, because high-frequency electric field with typical propagation wave length comparable to the length of actuator is applied, The inertia effect of actuator should be considered [46, 47]. Furthermore, since the strain/stress transfer between PZT patches and host structures is physically implemented through bonding layers, a more accurate model for improving sensitivity of 


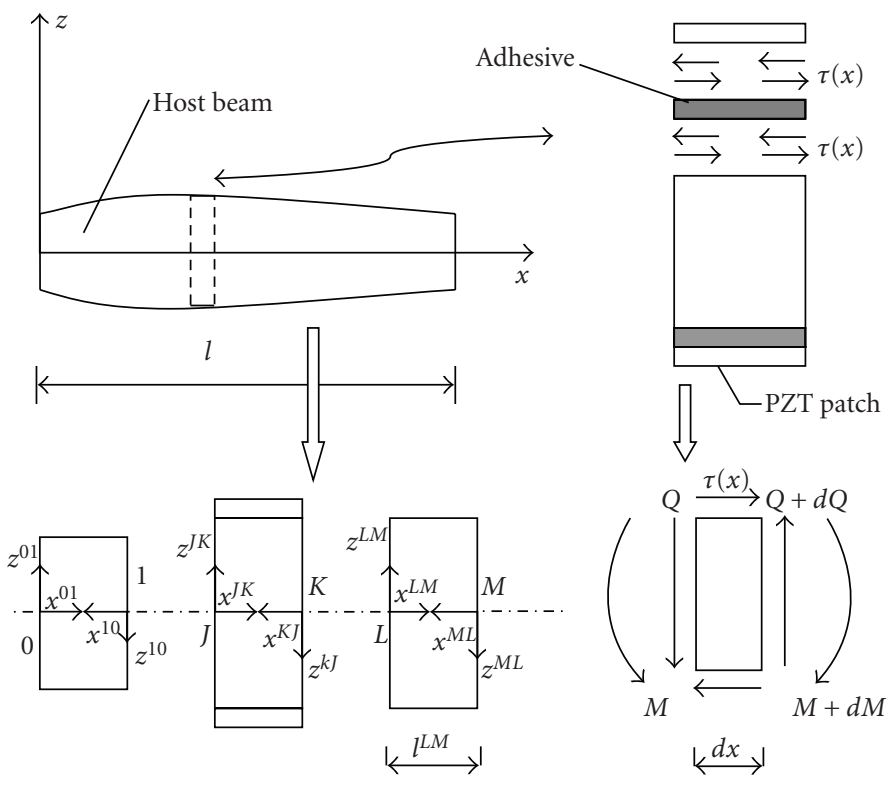

FIgUre 3: Nonhomogeneous beam with adhesively bonded PZT patches and local coordinates.

signature to damages by modulating the property of bonding layers should be developed. A classic shear lag solution was employed by Crawley and Luis [48] and Tong and Luo $[49,50]$ to analyze piezoelectric actuators as elements of intelligent structures. Bhalla and Soh [42] extended this method to develop an electromechanical impedance model of adhesively bonded piezo-transducers under quasistatic equilibrium and a good match between the predicted solutions and the measured data was observed. Under the consideration of both the inertia effect of actuator and the properties of the adhesive, Yan et al. [51-56], developed an accurate EMI model for detecting damages in classical rods [51], Mindlin-Herrmann rods [52], straight beams [54-56] and framed structures [53]. By taking an Euler-Bernoulli beam adhesively and symmetrically bonded with two PZT patches as an example, we illustrate this EMI model in the following.

As shown in Figure 3, a pair of PZT patches is bonded symmetrically and adhesively onto the top and bottom surfaces of a nonhomogeneous beam and is driven by a fixed alternating electric field out of phase. The equation of motion of the PZT patch, which is assumed to be in a state of $1 \mathrm{D}$ axial strain $[46,47]$, can be written out as

$$
E_{p} \frac{\partial^{2} u_{p}}{\partial x^{2}}-\frac{\tau}{h_{p}}=\rho_{p} \frac{\partial^{2} u_{p}}{\partial t^{2}},
$$

where $u$ is the axial displacement, $\rho$ and $E$ are the mass density and Young's modulus, and $h$ is the thickness (the subscript $p$ signifies the PZT patch). $\tau$ is the interfacial shear stress between the PZT patch (beam) and the adhesive and varies along the bonding length, and $t$ is the time variable. On the other hand, the bond layer is in the state of pure shear based on the shear lag model [48]:

$$
\tau=\frac{G}{h_{a}}\left(u_{p}-u_{s}\right), u_{s}=-\frac{h_{s}}{2} \frac{\partial w}{\partial x},
$$

where $G$ is the shear rigidity of the bonding layer, and $u_{s}$ and $w$ are the axial displacement and the transverse deflection of beam, respectively. The subscripts $s$ and $a$ correspond to the host beam and bonding layer, respectively.

For an Euler-Bernoulli beam, we then can get the following relations:

$$
\begin{gathered}
\frac{\partial M}{\partial x}+\tau h_{s}-Q=0, \quad \frac{\partial Q}{\partial x}=\rho_{s} A \frac{\partial^{2} w}{\partial t^{2}} \\
M=-E_{s} I \frac{\partial \psi}{\partial x}, \quad \psi=\frac{\partial w}{\partial x},
\end{gathered}
$$

where $M$ and $Q$ are the bending moment and shear force, respectively, and $I$ and $A$ are the moment of area and the cross sectional area, respectively. With due derivation, we can obtain the solution of transverse deformation as follows:

$$
\bar{w}=a_{1} \mathrm{e}^{\beta_{1} x}+a_{2} \mathrm{e}^{\beta_{2} x}+a_{3} \mathrm{e}^{\beta_{3} x}+d_{1} \mathrm{e}^{-\beta_{1} x}+d_{2} \mathrm{e}^{-\beta_{2} x}+d_{3} \mathrm{e}^{-\beta_{3} x},
$$

in which $a_{i}$ and $d_{i}(i=1,2,3)$ are undetermined constants, and $\beta_{i}(i=1,2,3)$ are defined in [55]. For an arbitrary beam segment $L M$ without bonded PZT patches, the well-known solution is expressed as

$$
\begin{aligned}
\bar{w}^{L M}= & a_{1}^{L M} e^{i k^{L M} x^{L M}}+a_{2}^{L M} e^{k^{L M} x^{L M}} \\
& +d_{1}^{L M} e^{-i k^{L M} x^{L M}}+d_{2}^{L M} e^{-k^{L M} x^{L M}},
\end{aligned}
$$

where $k^{L M}=\left[(\rho A)^{L M} \omega^{2} /\left(E_{s} I\right)^{L M}\right]^{1 / 4}$. Then, the method of reverberation-ray matrix (MRRM), which was originally proposed by $\mathrm{Pao}$ et al. [57-59] to study the transient response of a plane truss consisting of elastic members and then developed by Pao and Chen $[60,61]$ and Chen's research group $[62,63]$ for high-frequency dynamic analysis, is extended to investigate dynamics of the smart structure 
system. In MRRM, the first step is to establish a global scattering relation as follows:

$$
\mathbf{d}=\mathbf{S a}+\mathbf{Q}
$$

where $\mathbf{Q}$ is source vector, $\mathbf{d}=\left[\left(\mathbf{d}^{0}\right)^{\mathrm{T}},\left(\mathbf{d}^{1}\right)^{\mathrm{T}}, \ldots,\left(\mathbf{d}^{N-1}\right)^{\mathrm{T}}\right.$, $\left.\left(\mathbf{d}^{N}\right)^{\mathrm{T}}\right]^{\mathrm{T}}$ is the global vector associated with departing waves, and $\mathbf{a}=\left[\left(\mathbf{a}^{0}\right)^{\mathrm{T}},\left(\mathbf{a}^{1}\right)^{\mathrm{T}}, \ldots,\left(\mathbf{a}^{N-1}\right)^{\mathrm{T}},\left(\mathbf{a}^{N}\right)^{\mathrm{T}}\right]^{\mathrm{T}}$ is the global vector associated with arriving waves [57-63]. Then, according to unique physical reality of the smart structures, we can get the total phase relations:

$$
\mathbf{a}=\mathbf{P} \overline{\mathbf{d}},
$$

where $\mathbf{P}$ is the total phase shift matrix [57-63] and $\overline{\mathbf{d}}$ and d contain the same elements but are sequenced in different orders. The two vectors $\overline{\mathbf{d}}$ and $\mathbf{d}$ can be related through a permutation matrix $\mathbf{U}$ as

$$
\overline{\mathbf{d}}=\mathbf{U d},
$$

where $\mathbf{U}$ is a square matrix which contains one unit element in each row as well as one unit element in each column. From (10), (11), and (12), we obtain

$$
\mathbf{d}=\mathbf{R} \mathbf{d}+\mathbf{Q}, \quad \mathbf{R}=\mathbf{S P U},
$$

where $\mathbf{R}$ is called the reverberation-ray matrix [57-63]. It is then obtained that

$$
\mathbf{d}=(\mathbf{I}-\mathbf{R})^{-1} \mathbf{Q}, \mathbf{a}=\mathbf{S}^{-1}(\mathbf{d}-\mathbf{Q})=\mathbf{S}^{-1}\left[(\mathbf{I}-\mathbf{R})^{-1}-\mathbf{I}\right] \mathbf{Q} .
$$

Hence, all undetermined constants in (8) and (9) can be solved from (14). Note that the phase matrix $\mathbf{P}$ does not contain exponential functions with large positive indices and hence the numerical instability usually encountered in the conventional transfer matrix method (TMM) can be avoided. This is a crucial point for proper application of MRRM in high-frequency dynamic analysis of structures. Finally, the electric admittance (or electric impedance) of single PZT patch can be obtained as follows:

$$
\begin{aligned}
Y= & \frac{i \omega w_{p} l_{p}\left(\bar{\varepsilon}_{33}^{T}-d_{31}^{2} \bar{E}_{p}\right)}{h_{p}} \\
& +i \omega w_{p} d_{31} \bar{E}_{p}\left(\sum_{j=1}^{3} \frac{c_{j}}{\beta_{j}\left(a_{j}^{K J}-a_{j}^{J K}+d_{j}^{J K}-d_{j}^{K J}\right)}\right) .
\end{aligned}
$$

The detailed derivation can be found in [55] and omitted here for brevity.

Numerical results and experimental measurements have validated the effectiveness and precision of the present accurate EMI model. As observed in Figure 4, the two curves obtained by TMM and RMM, respectively, can hardly be distinguished in the low-frequency range less than about $13 \mathrm{kHz}$. However, in the high frequency range ( $f>13 \mathrm{kHz})$, numerical instability appears for TMM, in contrast to the well-performed MRRM.

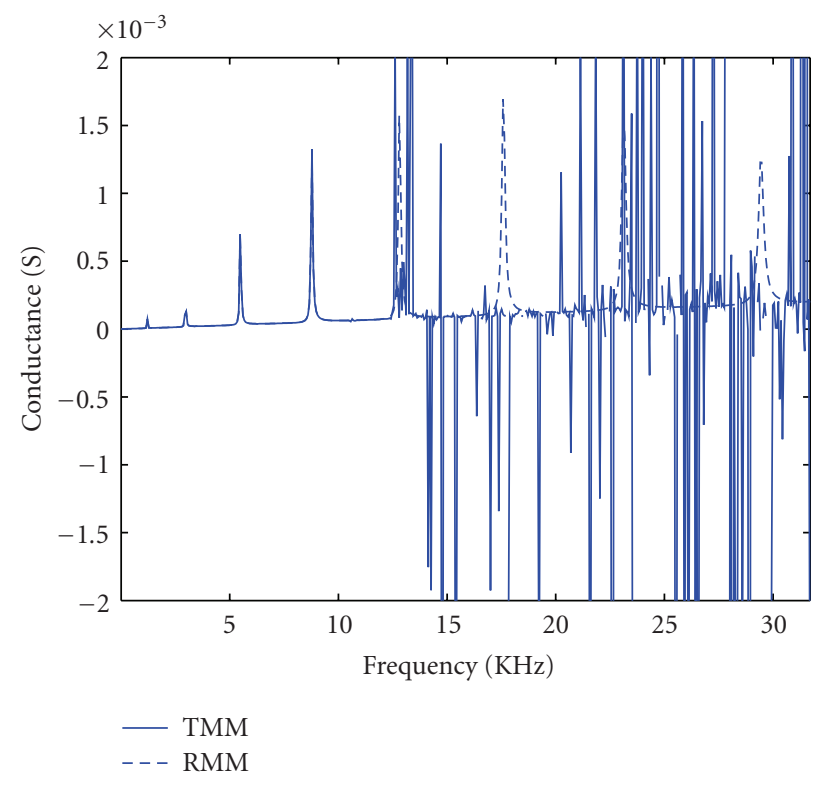

Figure 4: Comparison study with TMM.

The experimental results are further compared with analytical prediction of the present model in Figure 5 in the frequency range of $19-33 \mathrm{kHz}$. It is obvious that most experimentally observed peaks of impedance signatures related to prominent resonance frequencies can be predicted well using the analytical model. Furthermore, the present model can detect the damages in the beams (see Figure 6) and can locate the damages integrated with the curvature mode shape method [64] (see Figure 7). In Figures 6 and 7, D means effective uniform damage magnitude through certain beam segment [65]. The effects of interfacial properties are also investigated as shown in Figure 8 ( $\Gamma$ is the shear lag parameter $[48,55])$. Due to imperfect bonding, the impedance signatures change significantly. Furthermore, the accurate EMI model has been extended to MindlinHerrmann rods [52], Timoshenko beams [54], cracked continuous beams [56], and framed structures [53], and some significative research results have been obtained for structural health monitoring.

\section{Determination of Parameters}

In EMI technique, it is very important to select available PZT patches for structural health monitoring. Because one side of the PZT patch is to be bonded onto the monitored structure, the electrode of this side should be wrapped to the other side of the patch [5]. The size of the PZT should make the PZT transducers small enough not to be intrusive; that is, they do not significantly affect the dynamic properties of the host structures [66]. Thus, it is found that PZT patches of size ranging from 5 to $15 \mathrm{~mm}$ and thickness from 0.1 to $0.3 \mathrm{~mm}$ are best suitable for detecting damages in most structures such as steel and RC structures.

As mentioned in the previous section, the specific advantage of the EMI method over the other SHM techniques 


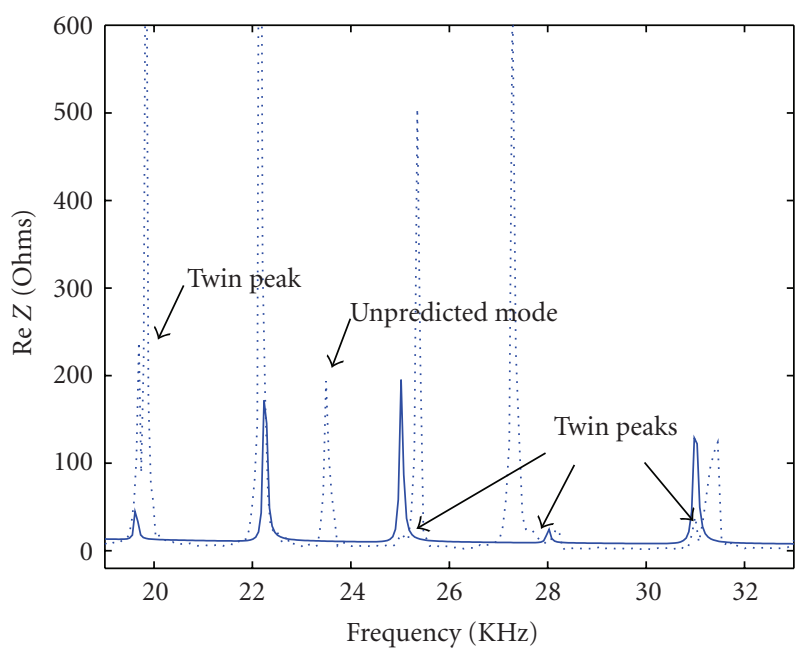

…. Experimental

- Analytical

(a)

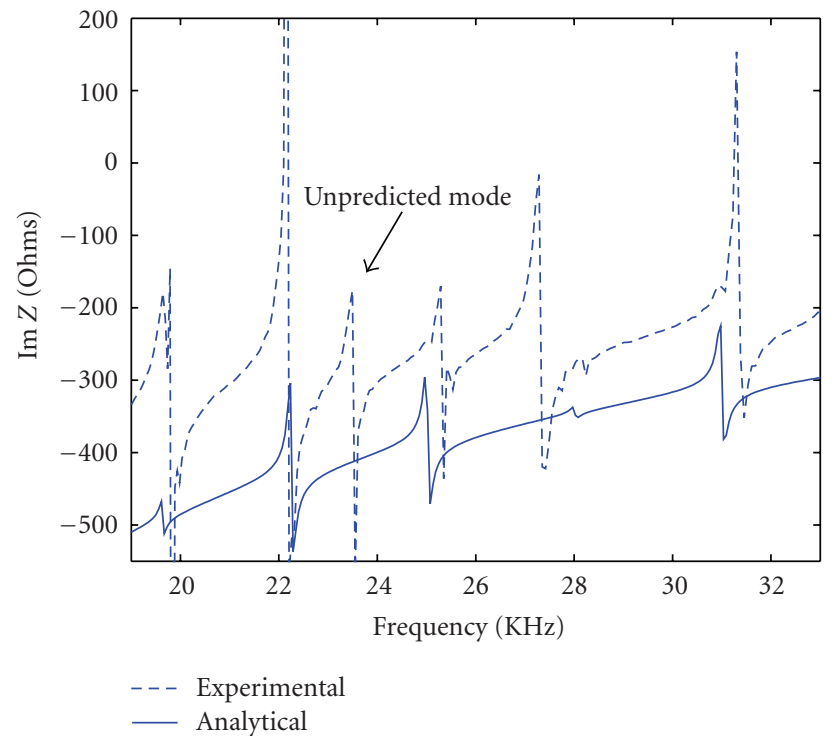

(b)

FIgURE 5: Experimental and analytical impedance spectra for a steel beam.

is its high sensitivity to incipient damages. Thus, it is necessary for the wavelength of excitation to be smaller than the characteristic length of the damage to be detected [67]. In general, the electrical impedance is measured at high frequencies in the range of $30-400 \mathrm{kHz}$ [20]. Under this high-frequency range, the wavelength of the excitation is small and sensitive enough to detect minor changes in the structural integrity. In EMI method, a frequency range containing 20-30 peaks seems suitable to choose, because a higher density of modes implies that there contains more structural information about the condition of a structure [12]. A frequency range higher than $200 \mathrm{kHz}$ is found to be favorable in localizing the sensing, while frequencies range lower than $70 \mathrm{kHz}$ covers a larger sensing area. Peairs

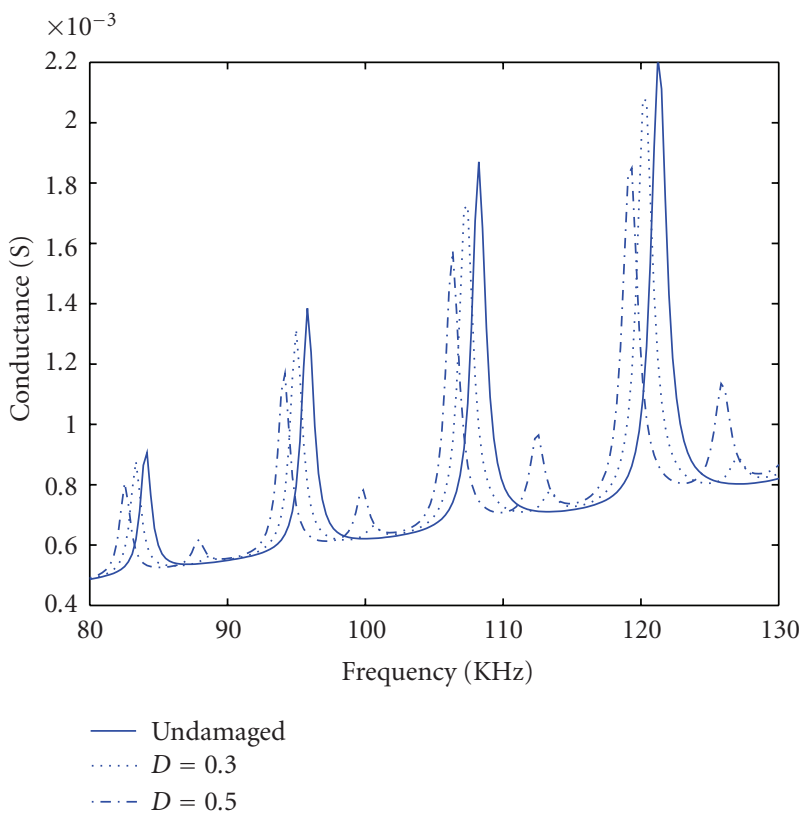

FIGURE 6: EM admittance signatures for various damage growth.

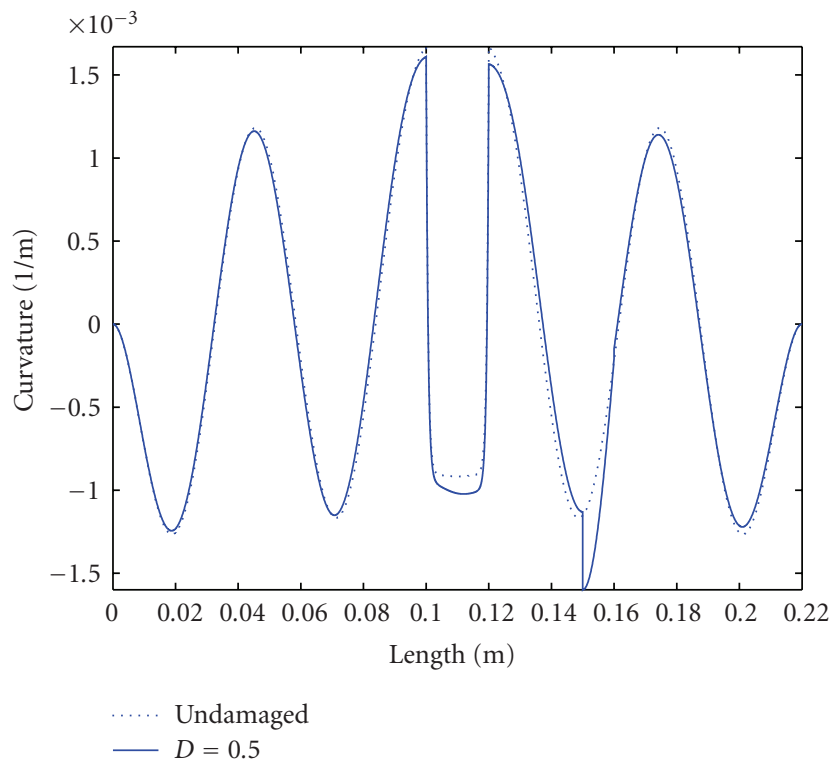

Figure 7: Curvature mode shapes along the length of the beam $(D=0.5)$.

et al. [68] remarked that the frequency ranges are usually selected by trial and error, which often involves inducing a removable amount of simulated damage. Their investigation for frequency range selection indicated that the ranges with the sensors/actuators resonances are better for monitoring with the impedance-based method.

Due to the high frequency of excitation used in EMI technique, the monitoring range of effective sensitivity of the PZT transducer is limited to its near vicinity [67]. Based on the knowledge acquired through various case studies, it has been estimated that the sensing area of a single 


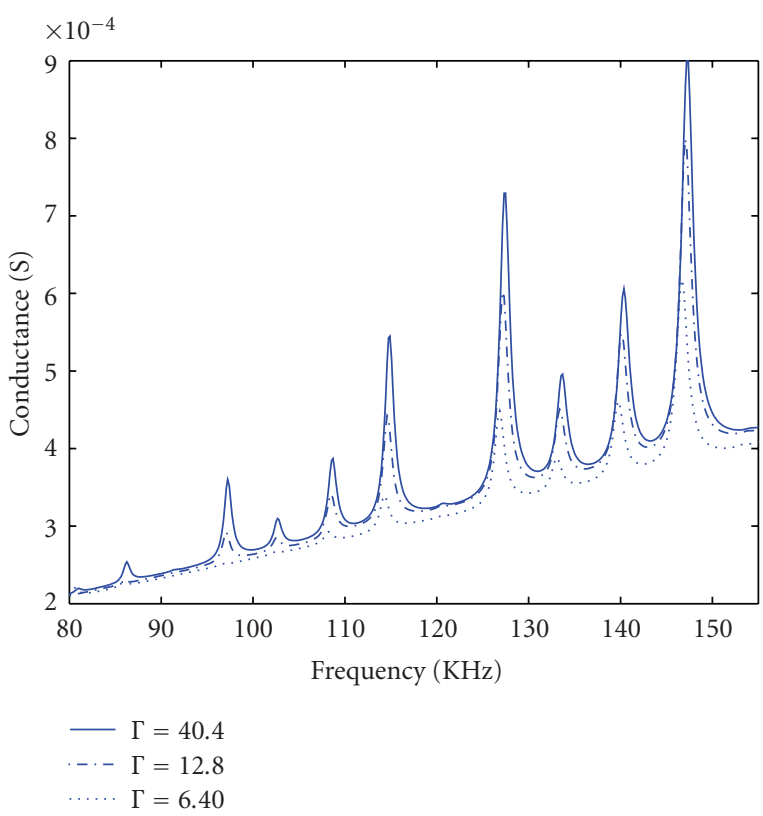

FIGURE 8: EM admittance signatures for various interfacial conditions.

PZT can vary anywhere from $0.4 \mathrm{~m}$ (sensing radius) on composite structures to $2 \mathrm{~m}$ on simple metal beams [20]. This localized nature of the sensing region provides an advantage in that the impedance sensor is less sensitive to boundary condition changes or any operational vibrations, which usually affect lower-order global modes. On the other hand, this characteristic of limited sensing range usually demands an active sensing network system for real world applications [69-73].

In real life, practical structures are constantly subjected to some form of external action such as external loading and temperature change. The experimental and statistical investigation showed that the EM admittance signature obtained for a constantly loaded structure is different from that obtained when damages are present in the structure and the susceptance signature is a better indicator than the conductance signature for detection damages in the structures [74].

Although regular piezoelectric patches have been found to be unsuitable for damage detection at cryogenic temperatures through a series of experiments and an alternative type of transducer based on smart materials should be sought [75], the EMI technique can still be used to actively monitor the damages in the structures, even with the presence of significant temperature variation in the normal temperature range $\left(25^{\circ} \mathrm{C}\right.$ to $\left.75^{\circ} \mathrm{C}\right)$.

Actually, almost all available transducers are small PZT patches in the EMI method, but some special sensors/actuators such as piezoceramic inertial actuators [76], piezoelectric stack transducers [77], and cement-based piezoelectric ceramic composites [78] are employed to satisfy practical demands or match to the host structures for structural health monitoring. Furthermore, the conventional EMI approach that consists of running wires between the local sensors and a data acquisition system will no longer be trivial. The cost associated with management and maintenance of such a system can be very high. Thus, an impedance-based wireless sensor node for structural health monitoring was developed by Mascarenas et al. [79] for the first time.

Although EMI method is very sensitive to minor damages in the structures and the EM signature change can be observed visually, it is necessary to employ statistical techniques to quantify it. It is wellknown that many types of nonparametric indices such as root mean square deviation (RMSD), mean absolute percentage deviation (MAPD), covariance (Cov), and correlation coefficient (CC) have been considered to quantify changes in the EMI admittance signatures [80]. Among these nonparametric indices, RMSD seems to be the most suitable damage index to characterize structural damages [80] and has been employed by many researchers for structural health monitoring [72, 74, 81-84]. Furthermore, a hybrid technique integrating neural network features with the impedance method has been proposed for somewhat quantitative damage analysis [85]. In this damage identification scheme, the impedance-based method detects and locates structural damage and provides damage indication in a green/red light form with the use of the modified RMSD firstly, and then the neural networks are used to estimate the severity of structural damage.

\section{Recent Applications}

Apart from some simple structures, such as axial rods [28$30]$, beams [29-31, 76, 86, 87], circular rings [32, 33], thin plates $[24,34,35,70,82,88,89]$, shells [36], and framed structures $[12,79,81,84]$, experimental implementation of the EMI-based structural health monitoring technique has been successfully conducted on several complex structures. The detection of cracks, loose connections of pipelines, damages in metallic structures, and debonds and delaminations in composites structures are reported by many researchers.

A masonry wall under step loading was investigated by using EMI method [15]. Five PZT patches are employed on one side of the wall. Four PZT patches are bonded in the corners and an additional PZT in the center. The multiple cracks of the wall appear with the loading increasing. It can be seen that EMI measurements are very sensitive to the presence of damage and from the observations and the damage metric charts the location of the damage can be approximately predicted.

Lim et al. [90] employed a new method for structural identification and damage detection using smart piezoelectric transducers. In this method, the mechanical impedance can be derived using 1-D and 2-D EMI coupling equations. The feasibility of damage detection was well demonstrated through the application on various laboratory-sized engineering structures such as an aluminum beam, an aluminum truss, and a concrete cube.

The experimental investigation for a concrete beam and a concrete slab by Tseng [73] showed that the PZT wafers were able to detect cracks on the surface as well as in depth. When the PZT patches are too far or too close to the damage, the wafers appear not capable of detecting the 
damage successfully. In addition, using RMSD index, this technique can give a good indication of the severity and location of the damage even when it is in the early stage. Similarly, Giurgiutiu et al. [91] applied piezoelectric wafer active sensors to aging aircraft structures to monitor the onset and progress of structural damage such as fatigue cracks and corrosion.

Pohl et al. [92] implemented an experimental and theoretical investigation to show the effectiveness of the impedance method in monitoring carbon fiber reinforced polymer (CFRP) composites. Damage, which was introduced by the low-speed impact, was detected by changes in the impedance signatures. The other type damages in CFRPs such as fiber fracture and delamination can also be identified by utilizing electrical impedance tomography [93].

The feasibility of the EMI sensing technique for strength gain monitoring of early-age concrete was also presented by Shin and Oh [94]. The experimental results showed that the EMI signature is sensitive to the strength development of early-age concrete and the RMSD value has also a strong correlation with the amount of the strength development of early-age concrete.

Due to the high-frequency excitation, the EMI-based health monitoring technique is very sensitive to minor defects in a structure and not affected by any far-field changes. The method has been successfully applied to various structures ranging from aerospace $[29,95]$ to civil structures $[1,7,14,15,94]$ and is ideal for tracking and online monitoring of damages in various structures

\section{Summary}

The overview of the development and applications of the electro-mechanical impedance-based structural health monitoring is presented in the paper. Although EMI method is very sensitive to incipient damages in the structures, it has been primarily developed only for qualitative health monitoring and fails to correlate changes in the signatures to physical parameters of structures. In order to develop an ideal robust damage detection scheme by using piezoelectric signatures, an analytical model for simulating the smart structural system is necessary for monitoring system. First, some conventional EMI models and their applications are discussed and an accurate EMI model based on MRRM is further suggested by authors. Comparison with the other numerical results and experimental data validates the present EMI model. The effects of PZT size, excitation frequency range, sensing range of PZT patch; and external action on EMI structural health monitoring technique are then remarked; the most part of discussions may also be found in other references. Finally, the feasibility of implementing the EMI method to detect damages in various lab-sized structures is demonstrated. In the future research, we should pay more attention on the testing of real structures under practical conditions rather than laboratory tests. Moreover, appropriate high-frequency structural theories shall be developed to adapt to the frequency range used in the EMItechnique, which is much higher than that implied in the conventional structural theories.

\section{Acknowledgments}

The work was sponsored by the National Natural Science Foundation of China (Grant no. 10725210), the National Basic Research Program of China (no. 2009CB623200), the Zhejiang Provincial Natural Science Foundation of China (no. Y107796), and the Ningbo Natural Science Foundation of China (nos. 2008A610101, 2009A610148).

\section{References}

[1] S. Park, C.-B. Yun, Y. Roh, and J.-J. Lee, "PZT-based active damage detection techniques for steel bridge components," Smart Materials and Structures, vol. 15, no. 4, pp. 957-966, 2006.

[2] R. D. Adams, P. Cawley, C. J. Pye, and B. J. Stone, "A vibration testing for non-destructively assessing the integrity of the structures," Journal of Mechanical Engineering Science, vol. 20, no. 2, pp. 93-100, 1978.

[3] P. Tan and L. Tong, "Identification of delamination in a composite beam using integrated piezoelectric sensor/actuator layer," Composite Structures, vol. 66, no. 1-4, pp. 391-398, 2004.

[4] M. Kisa, "Free vibration analysis of a cantilever composite beam with multiple cracks," Composites Science and Technology, vol. 64, no. 9, pp. 1391-1402, 2004.

[5] S. Bhalla and C. K. Soh, "High frequency piezoelectric signatures for diagnosis of seismic/blast induced structural damages," NDT and E International, vol. 37, no. 1, pp. 23-33, 2004.

[6] S. Bhalla, C. K. Soh, and Z. X. Liu, "Wave propagation approach for NDE using surface bonded piezoceramics," NDT and E International, vol. 38, no. 2, pp. 143-150, 2005.

[7] V. Giurgiutiu, A. Reynolds, and C. A. Rogers, "Experimental investigation of E/M impedance health monitoring for spotwelded structural joints," Journal of Intelligent Material Systems and Structures, vol. 10, no. 10, pp. 802-812, 1999.

[8] G. Park, A. C. Rutherford, H. Sohn, and C. R. Farrar, "An outlier analysis framework for impedance-based structural health monitoring," Journal of Sound and Vibration, vol. 286, no. 1-2, pp. 229-250, 2005.

[9] T. R. Fasel, H. Sohn, G. Park, and C. R. Farrar, "Active sensing using impedance-based ARX models and extreme value statistics for damage detection," Earthquake Engineering and Structural Dynamics, vol. 34, no. 7, pp. 763-785, 2005.

[10] S. Ritdumrongkul, M. Abe, Y. Fujino, and T. Miyashita, "Quantitative health monitoring of bolted joints using a piezoceramic actuator-sensor," Smart Materials and Structures, vol. 13, no. 1, pp. 20-29, 2004.

[11] A. S. K. Naidu and C. K. Soh, "Damage severity and propagation characterization with admittance signatures of piezo transducers," Smart Materials and Structures, vol. 13, no. 2, pp. 393-403, 2004.

[12] F. P. Sun, Z. Chaudhry, C. Liang, and C. A. Rogers, "Truss structure integrity identification using PZT sensor-actuator," Journal of Intelligent Material Systems and Structures, vol. 6, no. 1, pp. 134-139, 1995.

[13] J. W. Ayres, F. Lalande, Z. Chaudhry, and C. A. Rogers, "Qualitative impedance-based health monitoring of civil infrastructures," Smart Materials and Structures, vol. 7, no. 5, pp. 599-605, 1998.

[14] C. K. Soh, K. K.-H. Tseng, S. Bhalla, and A. Gupta, "Performance of smart piezoceramic patches in health monitoring of 
a RC bridge," Smart Materials and Structures, vol. 9, no. 4, pp. 533-542, 2000.

[15] G. Park, H. H. Cudney, and D. J. Inman, "Impedance-based health monitoring of civil structural components," Journal of Infrastructure Systems, vol. 6, no. 4, pp. 153-160, 2000.

[16] G. Park, H. H. Cudney, and D. J. Inman, "Feasibility of using impedance-based damage assessment for pipeline structures," Earthquake Engineering and Structural Dynamics, vol. 30, no. 10, pp. 1463-1474, 2001.

[17] G. Park, D. E. Muntges, and D. J. Inman, "Self-monitoring and self-healing jointed structures," Key Engineering Materials, no. 204-205, pp. 75-84, 2001.

[18] C. Bois and C. Hochard, "Monitoring of laminated composites delamination based on electro-mechanical impedance measurement," Journal of Intelligent Material Systems and Structures, vol. 15, no. 1, pp. 59-67, 2004.

[19] C. Bois, P. Herzog, and C. Hochard, "Monitoring a delamination in a laminated composite beam using in-situ measurements and parametric identification," Journal of Sound and Vibration, vol. 299, no. 4-5, pp. 786-805, 2007.

[20] D. Montalvão, N. M. M. Maia, and A. M. R. Ribeiro, "A review of vibration-based structural health monitoring with special emphasis on composite materials," The Shock and Vibration Digest, vol. 38, no. 4, pp. 295-324, 2006.

[21] G. Park, H. Sohn, C. R. Farrar, and D. J. Inman, "Overview of piezoelectric impedance-based health monitoring and path forward," The Shock and Vibration Digest, vol. 35, no. 6, pp. 451-463, 2003.

[22] C. Liang, F. P. Sun, and C. A. Rogers, "Impedance method for dynamic analysis of active material systems," Journal of Vibration and Acoustics, vol. 116, no. 1, pp. 120-128, 1994.

[23] C. Liang, F. P. Sun, and C. A. Rogers, "Coupled electromechanical analysis of adaptive material systems-determination of the actuator power consumption and system energy transfer," Journal of Intelligent Material Systems and Structures, vol. 5, no. 1, pp. 12-20, 1994.

[24] S.-W. Zhou, C. Liang, and C. A. Rogers, "An impedance-based system modeling approach for induced strain actuator-driven structures," Journal of Vibration and Acoustics, vol. 118, no. 3, pp. 323-331, 1996.

[25] S.-W. Zhou, C. Liang, and C. A. Rogers, "Integration and design of piezoceramic elements in intelligent structures," Journal of Intelligent Material Systems and Structures, vol. 6, no. 6, pp. 733-743, 1995.

[26] S. Bhalla and C. K. Soh, "Structural health monitoring by piezo-impedance transducers. I. Modeling," Journal of Aerospace Engineering, vol. 17, no. 4, pp. 154-165, 2004.

[27] S. Bhalla and C. K. Soh, "Structural health monitoring by piezo-impedance transducers. II. Applications," Journal of Aerospace Engineering, vol. 17, no. 4, pp. 166-175, 2004.

[28] G. Park, H. H. Cudney, and D. J. Inman, "An integrated health monitoring technique using structural impedance sensors," Journal of Intelligent Material Systems and Structures, vol. 11, no. 6, pp. 448-455, 2000.

[29] V. Giurgiutiu and A. N. Zagrai, "Embedded self-sensing piezoelectric active sensors for on-line structural identification," Journal of Vibration and Acoustics, vol. 124, no. 1, pp. 116-125, 2002.

[30] K. K.-H Tseng and L. Wang, "Impedance-based method for nondestructive damage identification," Journal of Engineering Mechanics, vol. 131, no. 1, pp. 58-64, 2005.

[31] Y.-D. Kuang, G.-Q. Li, and C.-Y. Chen, "An admittance function of active piezoelectric elements bonded on a cracked beam," Journal of Sound and Vibration, vol. 298, no. 1-2, pp. 393-403, 2006.

[32] F. Lalande, Z. Chaudhry, and C. A. Rogers, "Impedancebased modelling of induced strain actuators bonded on ring structures," Journal of Sound and Vibration, vol. 201, no. 2, pp. 169-187, 1997.

[33] Y.-D. Kuang, G.-Q. Li, and C.-Y. Chen, "Dynamic analysis of actuator-driven circular arch or ring using impedance elements," Smart Materials and Structures, vol. 15, no. 3, pp. 869-876, 2006.

[34] A. N. Zagrai and V. Giurgiutiu, "Electro-mechanical impedance method for crack detection in thin plates," Journal of Intelligent Material Systems and Structures, vol. 12, no. 10, pp. 709-718, 2001.

[35] J. F. Xu, Y. Yang, and C. K. Soh, "Electromechanical impedance-based structural health monitoring with evolutionary programming," Journal of Aerospace Engineering, vol. 17, no. 4, pp. 182-193, 2004.

[36] Y. Yang and Y. Hu, "Electromechanical impedance modeling of PZT transducers for health monitoring of cylindrical shell structures," Smart Materials and Structures, vol. 17, no. 1, Article ID 015005, 11 pages, 2008.

[37] Y. G. Xu and G. R. Liu, "A modified electro-mechanical impedance model of piezoelectric actuator-sensors for debonding detection of composite patches," Journal of Intelligent Material Systems and Structures, vol. 13, no. 6, pp. 389396, 2002.

[38] H. A. Winston, F. Sun, and B. S. Annigeri, "Structural health monitoring with piezoelectric active sensors," Journal of Engineering for Gas Turbines and Power, vol. 123, no. 2, pp. 353-358, 2001.

[39] A. S. K. Naidu and C. K. Soh, "Identifying damage location with admittance signatures of smart piezo-transducers," Journal of Intelligent Material Systems and Structures, vol. 15, no. 8, pp. 627-642, 2004.

[40] A. V. G. Madhav and C. K. Soh, "An electromechanical impedance model of a piezoceramic transducer-structure in the presence of thick adhesive bonding," Smart Materials and Structures, vol. 16, no. 3, article 14, pp. 673-686, 2007.

[41] E. C. Pestel and F. A. Leckie, Matrix Methods in Elasto Mechanics, McGraw-Hill, New York, NY, USA, 1963.

[42] S. Bhalla and C. K. Soh, "Electromechanical impedance modeling for adhesively bonded piezo-transducers," Journal of Intelligent Material Systems and Structures, vol. 15, no. 12, pp. 955-972, 2004.

[43] V. Giurgiutiu, "Tuned lamb wave excitation and detection with piezoelectric wafer active sensors for structural health monitoring," Journal of Intelligent Material Systems and Structures, vol. 16, no. 4, pp. 291-305, 2005.

[44] X. P. Qing, H.-L. Chan, S. J. Beard, T. K. Ooi, and S. A. Marotta, "Effect of adhesive on the performance of piezoelectric elements used to monitor structural health," International Journal of Adhesion and Adhesives, vol. 26, no. 8, pp. 622-628, 2006.

[45] W. Yan, J. B. Cai, and W. Q. Chen, "Monitoring interfacial defects in a composite beam using impedance signatures," Journal of Sound and Vibration, vol. 326, no. 1-2, pp. 340-352, 2009.

[46] X. D. Wang and G. L. Huang, "Wave propagation in electromechnical structures: induced by surface-bonded piezoelectric actuators," Journal of Intelligent Material System and Structures, vol. 12, pp. 105-115, 2001.

[47] X. D. Wang and G. L. Huang, "The coupled dynamic behavior of piezoelectric sensors bonded to elastic media," Journal of 
Intelligent Material Systems and Structures, vol. 17, no. 10, pp. 883-894, 2006.

[48] E. F. Crawley and J. de Luis, "Use of piezoelectric actuators as elements of intelligent structures," AIAA Journal, vol. 25, no. 10, pp. 1373-1385, 1987.

[49] L. Tong and Q. Luo, "Exact dynamic solutions to piezoelectric smart beams including peel stresses. I. Theory and application," International Journal of Solids and Structures, vol. 40, no. 18, pp. 4789-4812, 2003.

[50] Q. Luo and L. Tong, "Exact dynamic solutions to piezoelectric smart beams including peel stresses. II. Numerical results, comparison and approximate solution," International Journal of Solids and Structures, vol. 40, no. 18, pp. 4813-4836, 2003.

[51] W. Yan, W.-Q. Chen, C.-W. Lim, and J.-B. Cai, "Damage detection with high-frequency electric impedance signals," Journal of Zhejiang University, vol. 41, no. 1, pp. 6-11, 2007 (Chinese).

[52] W. Yan, C. W. Lim, W. Q. Chen, and J. B. Cai, "Modeling of EMI response of damaged Mindlin-Herrmann rod," International Journal of Mechanical Sciences, vol. 49, no. 12, pp. 13551365, 2007.

[53] W. Yan, C. W. Lim, W. Q. Chen, and J. B. Cai, "A coupled approach for damage detection of framed structures using piezoelectric signature," Journal of Sound and Vibration, vol. 307, no. 3-5, pp. 802-817, 2007.

[54] W. Yan, C. W. Lim, J. B. Cai, and W. Q. Chen, "An electromechanical impedance approach for quantitative damage detection in Timoshenko beams with piezoelectric patches," Smart Materials and Structures, vol. 16, no. 4, pp. 1390-1400, 2007.

[55] W. Yan, W. Q. Chen, J. B. Cai, and C. W. Lim, "Quantitative structural damage detection using high-frequency piezoelectric signatures via the reverberation matrix method," International Journal for Numerical Methods in Engineering, vol. 71, no. 5, pp. 505-528, 2007.

[56] W. Yan, W. Q. Chen, C. W. Lim, and J. B. Cai, "Application of EMI technique for crack detection in continuous beams adhesively bonded with multiple piezoelectric patches," Mechanics of Advanced Materials and Structures, vol. 15, no. 1, pp. 1-11, 2008.

[57] S. M. Howard and Y.-H. Pao, "Analysis and experiments on stress waves in planar trusses," Journal of Engineering Mechanics, vol. 124, no. 8, pp. 884-890, 1998.

[58] Y.-H. Pao, D.-C. Keh, and S. M. Howard, "Dynamic response and wave propagation in plane trusses and frames," AIAA journal, vol. 37, no. 5, pp. 594-603, 1999.

[59] J.-F. Chen and Y.-H. Pao, "Effects of causality and joint conditions on method of reverberation-ray matrix," AIAA Journal, vol. 41, no. 6, pp. 1138-1142, 2003.

[60] Y.-H. Pao, W.-Q. Chen, and X.-Y. Su, "The reverberation-ray matrix and transfer matrix analyses of unidirectional wave motion," Wave Motion, vol. 44, no. 6, pp. 419-438, 2007.

[61] Y.-H. Pao and W.-Q. Chen, "Elastodynamic theory of framed structures and reverberation-ray matrix analysis," Acta Mechanica, vol. 204, no. 1-2, pp. 61-79, 2009.

[62] Y. Q. Guo and W. Q. Chen, "Dynamic analysis of space structures with multiple tuned mass dampers," Engineering Structures, vol. 29, no. 12, pp. 3390-3403, 2007.

[63] J. Q. Jiang and W. Q. Chen, "Reverberation-ray analysis of moving or distributive loads on a non-uniform elastic bar," Journal of Sound and Vibration, vol. 319, no. 1-2, pp. 320-334, 2009.
[64] A. K. Pandey, M. Biswas, and M. M. Samman, "Damage detection from changes in curvature mode shapes," Journal of Sound and Vibration, vol. 145, no. 2, pp. 321-332, 1991.

[65] U. Lee and J. Shin, "A frequency-domain method of structural damage identification formulated from the dynamic stiffness equation of motion," Journal of Sound and Vibration, vol. 257, no. 4, pp. 615-634, 2002.

[66] G. Park and D. J. Inman, "Structural health monitoring using piezoelectric impedance measurements," Philosophical Transactions of the Royal Society A, vol. 365, no. 1851, pp. 373392, 2007.

[67] J. Esteban and C. A. Rogers, "Wave localization due to material damping," Computer Methods in Applied Mechanics and Engineering, vol. 177, no. 1-2, pp. 93-107, 1999.

[68] D. M. Peairs, P. A. Tarazaga, and D. J. Inman, "Frequency range selection for impedance-based structural health monitoring," Journal of Vibration and Acoustics, vol. 129, no. 6, pp. 701-709, 2007.

[69] S. Park, C.-B. Yun, and Y. Roh, "Damage diagnostics on a welded zone of a steel truss member using an active sensing network system," NDT and E International, vol. 40, no. 1, pp. 71-76, 2007.

[70] G. Park, C. R. Farrar, F. L. Di Scalea, and S. Coccia, "Performance assessment and validation of piezoelectric activesensors in structural health monitoring," Smart Materials and Structures, vol. 15, no. 6, pp. 1673-1683, 2006.

[71] V. G. M. Annamdas and C. K. Soh, "Three-dimensional electromechanical impedance model for multiple piezoceramic transducers-structure interaction," Journal of Aerospace Engineering, vol. 21, no. 1, pp. 35-44, 2008.

[72] K. K.-H Tseng, "Impedance-based non-destructive and nonparametric infrastructural performance evaluation," Experimental Mechanics, vol. 44, no. 1, pp. 109-112, 2004.

[73] C. C. Cheng and C. C. Lin, "An impedance approach for vibration response synthesis using multiple PZT actuators," Sensors and Actuators A, vol. 118, no. 1, pp. 116-126, 2005.

[74] V. G. M. Annamdas, Y. Yang, and C. K. Soh, "Influence of loading on the electromechanical admittance of piezoceramic transducers," Smart Materials and Structures, vol. 16, no. 5, pp. 1888-1897, 2007.

[75] K. K.-H Tseng, M. L. Tinker, J. O. Lassiter, and D. M. Peairs, "Temperature dependency of impedance-based nondestructive testing," Experimental Techniques, vol. 27, no. 5, pp. 33-36, 2003.

[76] S. F. Ling and Y. Xie, "Detection mechanical impedance of structures using the sensing capability of a piezoceramic inertial actuator," Sensors and Actuators A, vol. 93, pp. 243249, 2001.

[77] D. Mayer, H. Atzrodt, S. Herold, and M. Thomaier, "An approach for the model based monitoring of piezoelectric actuators," Computers and Structures, vol. 86, no. 3-5, pp. 314321, 2008.

[78] F. Xing, B. Dong, and Z. Li, "Impedance spectroscopic studies of cement-based piezoelectric ceramic composites," Composites Science and Technology, vol. 68, no. 12, pp. 24562460, 2008.

[79] D. L. Mascarenas, M. D. Todd, G. Park, and C. R. Farrar, "Development of an impedance-based wireless sensor node for structural health monitoring," Smart Materials and Structures, vol. 16, no. 6, pp. 2137-2145, 2007.

[80] K. K.-H. Tseng and A. S. K. Naidu, "Non-parametric damage detection and characterization using smart piezoceramic 
material," Smart Materials and Structures, vol. 11, no. 3, pp. 317-329, 2002.

[81] S. Bhalla and C. K. Soh, "Structural impedance based damage diagnosis by piezo-transducers," Earthquake Engineering and Structural Dynamics, vol. 32, no. 12, pp. 1897-1916, 2003.

[82] V. Giurgiutiu and A. Zagrai, "Damage detection in thin plates and aerospace structures with the electro-mechanical impedance method," Structural Health Monitoring, vol. 4, no. 2, pp. 99-118, 2005.

[83] M.-H. Kim, "A smart health monitoring system with application to welded structures using piezoceramic and fiber optic transducers," Journal of Intelligent Material Systems and Structures, vol. 17, no. 1, pp. 35-44, 2006.

[84] A. C. Rutherford, G. Park, and C. R. Farrar, "Non-linear feature identifications based on self-sensing impedance measurements for structural health assessment," Mechanical Systems and Signal Processing, vol. 21, no. 1, pp. 322-333, 2007.

[85] V. Lopes Jr., G. Park, H. H. Cudney, and D. J. Inman, "Impedance-based structural health monitoring with artificial neural networks," Journal of Intelligent Material Systems and Structures, vol. 11, no. 3, pp. 206-214, 2000.

[86] Y.-D. Kuang, G.-Q. Li, and C.-Y. Chen, "Admittance function of active piezoelectric elements bonded on a curved cracked beam," Journal of Intelligent Material Systems and Structures, vol. 19, no. 2, pp. 181-191, 2008.

[87] V. Giurgiutiu and A. N. Zagrai, "Characterization of piezoelectric wafer active sensors," Journal of Intelligent Material Systems and Structures, vol. 11, no. 12, pp. 959-976, 2000.

[88] Y. Yang, J. Xu, and C. K. Soh, "Generic impedance-based model for structure-piezoceramic interacting system," Journal of Aerospace Engineering, vol. 18, no. 2, pp. 93-101, 2005.

[89] K. J. Xing and C.-P. Fritzen, "Monitoring of growing fatigue damage using the E/M impedance method," Key Engineering Materials, vol. 347, pp. 153-158, 2007.

[90] Y. Y. Lim, S. Bhalla, and C. K. Soh, "Structural identification and damage diagnosis using self-sensing piezo-impedance transducers," Smart Materials and Structures, vol. 15, no. 4, pp. 987-995, 2006.

[91] V. Giurgiutiu, A. Zagrai, and J. J. Bao, "Damage identification in aging aircraft structures with piezoelectric wafer active sensors," Journal of Intelligent Material Systems and Structures, vol. 15, no. 9-10, pp. 673-687, 2004.

[92] J. Pohl, S. Herold, G. Mook, and F. Michel, "Damage detection in smart CFRP composites using impedance spectroscopy," Smart Materials and Structures, vol. 10, no. 4, pp. 834-842, 2001.

[93] R. Schueler, S. P. Joshi, and K. Schulte, "Damage detection in CFRP by electrical conductivity mapping," Composites Science and Technology, vol. 61, no. 6, pp. 921-930, 2001.

[94] S. W. Shin and T. K. Oh, "Application of electro-mechanical impedance sensing technique for online monitoring of strength development in concrete using smart PZT patches," Construction and Building Materials, vol. 23, no. 2, pp. 11851188, 2009.

[95] J. D. R. V. De Moura Jr. and V. Steffen Jr., "Impedance-based health monitoring for aeronautic structures using statistical meta-modeling," Journal of Intelligent Material Systems and Structures, vol. 17, no. 11, pp. 1023-1036, 2006. 

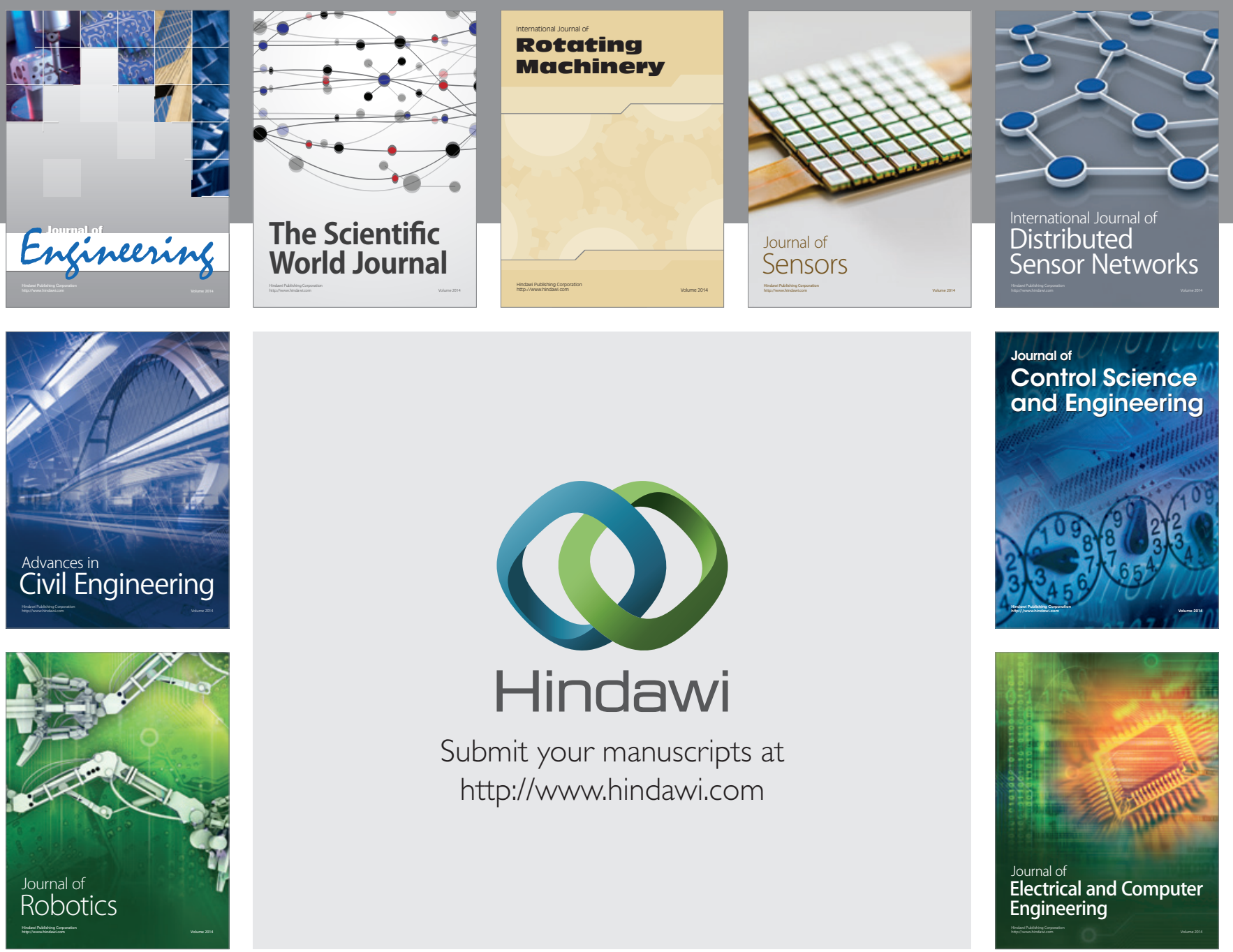

Submit your manuscripts at

http://www.hindawi.com
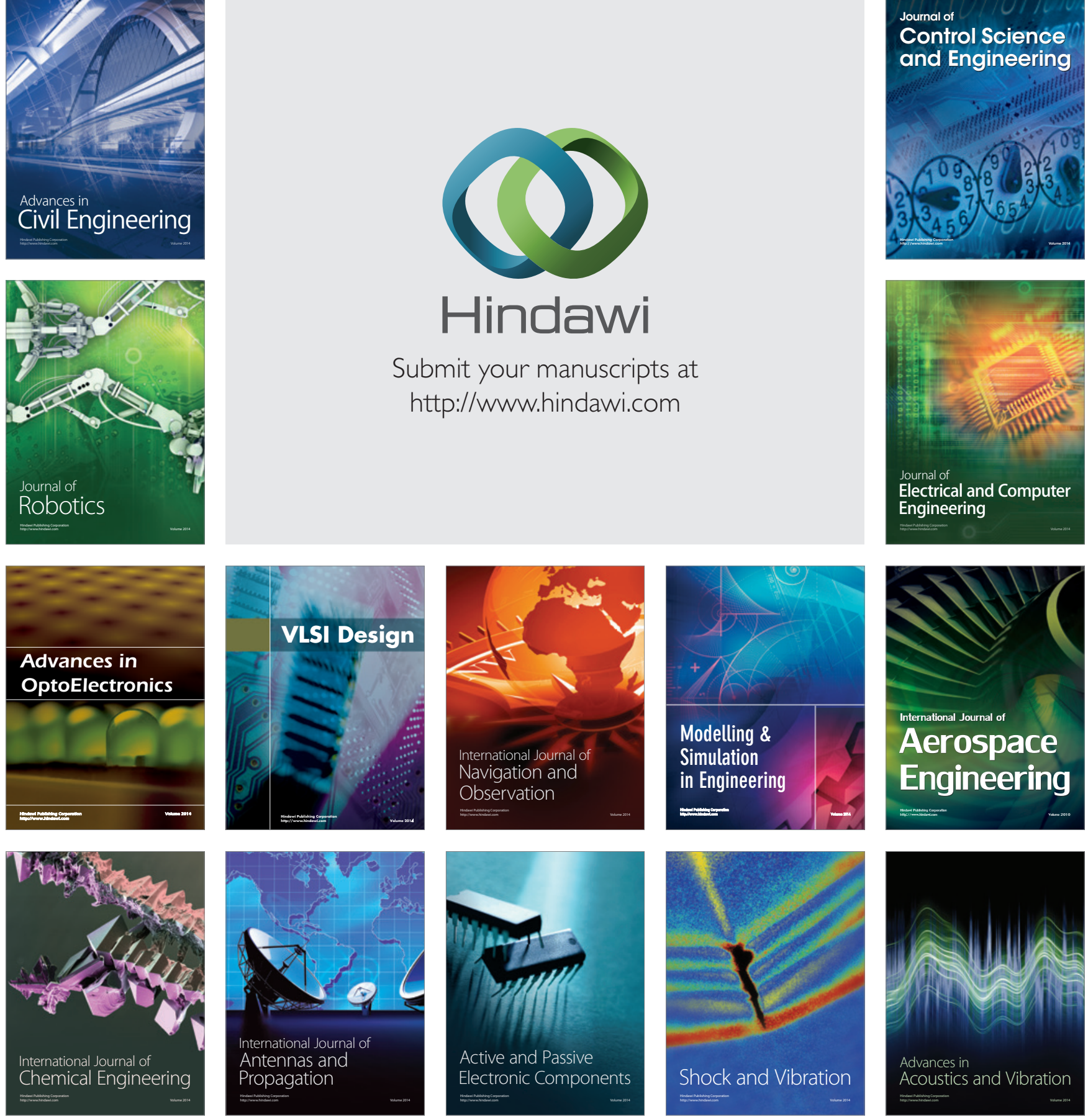